\title{
To the determination of non-washable speed in the channels bed consisting of disconnected soils
}

\author{
Luqmon Samiev ${ }^{*}$, Qudratjon Rakhimov, Zaytuna Ibragimova, and Davron Allayorov \\ Tashkent Institute of Irrigation and Agricultural Mechanization Engineers, Tashkent, Uzbekistan
}

\begin{abstract}
This article analyzes the factors that influence the deformation process in the channel. When assessing the deformation process in channels consisting of disconnected soils, the method for determining nonwashable speed was analyzed, taking into account the trapezoidal shape of the channel, and, based on laboratory studies, a dependence was proposed for determining the non-washable speed. The values of the proposed dependencies are compared with the calculated values of the formulas of I.I. Levi, C.E. Mirtskhulava, V.A. Velikanova, B.I. Studenichnikov and A.M. Latyshenkov and obtained positive results. The proposed dependencies for the determination of non-washable speed are improved, taking into account turbulence and the laws of velocity distribution over the stream's depth. In the experimental researches, were used sand particles with different diameters $\quad d \leq 0.315 \mathrm{~mm} ; \quad 0.315 \mathrm{~mm}<d \leq 0.63 \mathrm{~mm}$; $0.63 \mathrm{~mm}<d \leq 1.25 \mathrm{~mm} \quad 1.25 \mathrm{~mm}<d \leq 2.5 \mathrm{~mm} \quad 2.5 \mathrm{~mm}<d \leq 5.0 \mathrm{~mm}$. Based on the analysis of the experimental data, the coefficients are as follows: $\eta_{1}=1.41$ for the bottom of the channel and $\eta_{2}=1.52$ for side slopes. The reliability of the results is justified by comparing the proposed calculation method with a study of other authors. Based on the research, constructed a plot of the velocity distribution and the depth of the stream. In these diagrams, preservation of the change in velocity along the depth of the flow was observed under various modes of motion. In all experiments, a process was observed-the smallest value of the flow velocity at the bottom and the highest at a depth of $(0.8-0.9) \mathrm{h}$ from the water level.
\end{abstract}

\section{Introduction}

River sediments are an integral part of water resources; with the efficient use of water resources, it is necessary to evaluate these sediments' negative and positive sides.

One of the most important environmental tasks of the integrated use of water resources and reducing the negative impacts of river sediments at a water facility is to evaluate their quantity indicator. In this regard, the development of methods for calculating and predicting deformations in the conditions of steady and unsteady flows in channels (canals, reservoirs, shallow rivers, etc.) is of particular importance. Several studies have been carried out in this

* Corresponding author: 1.samiyev@tiiame.uz 
direction in the USA, the Netherlands, Germany, France, Japan, Russia, China, South Korea, and other developed countries to develop effective methods for projecting open channels operating in stationary and non-stationary states, to prevent the occurring deformations in them and to ensure their authenticity. One of the main tasks is the prediction of deformation processes in channels with steady and unsteady movements of soil channels taking into account turbulence of the flow and wind wave parameters, the development of new methods for determining the channel capacity.

The following authors (V.N. Goncharov, G.I. Shamov, I.I. Levi, I.E. Egiazarov, C.E. Mirtskhulava, A.V. Magomedova, A.M. Mukhamedov, V.S. Borovkov ,Kh.Z. Ishanov, A.M. Arifzhanov, Yu.M. Umarov, and others) were obtained several empirical formulas for determining the non-washing velocity in connected and disconnected soils of the flow. Known positive results have been achieved by introducing an empirical coefficient that considers various factors affecting soil erosion or a different approach to the ultimate equilibrium of particles.

To date, in the country in the applied open ground channels, despite extensive research in this direction, insufficient attention has been paid to the ongoing deformations in the channel arising from an unsteady flow. Therefore, due to the influence of an unsteady flow, the throughput in these channels is reduced due to the intensity of the deformation process. Therefore, the proposal of the correct calculation of the assessment of the deformation of the channel in the design of large irrigation systems is important. The study of this problem is now justified by a complete calculation of the factors that express this process in many cases.

\section{Methods}

The research used the calculation of the open channel deformation of steady and unsteady flows, system analysis, statistical processing of the results, methods of hydraulic and mathematical modeling.

Main part. Assessing the deformation process of the channels based on the method of permissible speeds. According to the requirements for the channels, the hydraulic elements of the projected soil channel must correspond to the average speed of such movement. According to the estimation of the siltation rate in the channels, taking the recommendations of the literature, the following condition must be fulfilled, non-washable speeds are considered [1-3].

$$
\vartheta_{l} \leq \vartheta \leq \vartheta_{y}
$$

there: $\vartheta_{l}$ is sedimentation speed; $\vartheta_{y}$ is non-erosion speed; $\vartheta_{\text {is average speed. }}$

When designing soil channels, the proper installation of non-blurring speeds is of particular importance. In this direction, there are developments by several authors, including Levy [4], Shamov [5], Karaushev [6], who proposed calculation formulas for determining the non-blurring speed based on the results of experiments under different flow and soil conditions. The widespread use of these formulas is that in many cases, they are obtained based on experiments, giving an accurate result only in boundary conditions. The achievement of these studies is that the proposed formulas are derived based on an analysis of the conditions for the equality of the forces of resistance to movement, as well as the forces of individual particles and stresses from the turbulent flow, taking into account the stress state of the soil from the total mass of the bottom of the channel.

One of the common calculation formulas in this direction is the proposed formulas of Mirzhulav; they have the form. 


$$
\begin{gathered}
v_{y}=\left(\lg \frac{8.8 h}{d}\right) \sqrt{\frac{2 m}{0.44 \rho n}\left[g\left(\rho_{g r}-\rho\right) d+2 C_{k m .}^{n} k\right]} \\
v_{\Delta y}=1.25 \sqrt{\frac{2 m}{0.44 \rho n}\left[g\left(\rho_{g r}-\rho\right) d+2 C_{k . n}^{n} k\right]}
\end{gathered}
$$

there: $v_{y}$ is permissible non-washable flow velocity over the cross-section, $\mathrm{m} / \mathrm{s} ; v_{\Delta y}$ is permissible flow velocity at the roughness of the channel, $\Delta \mathrm{m} / \mathrm{s} ; \quad \rho_{g r}$ and $\rho$ is correspondingly density of soil particle and water, $\mathrm{kg} / \mathrm{m}^{3} ; d$ is the average diameter of the soil particles, $\mathrm{m} ; C_{k n}^{n}$ is cohesive soil coefficient compound, is the coefficient of connection of non-connected soil, i.e., this parameter $(\mathrm{d}<0.25 \mathrm{~mm})$ with fine-grained soil takes into account the adhesion force, $\mathrm{Pa}$;

$m$ is coefficient taking into account the influence of the colloidal condition of sediment in the composition of the flow on the erosion ability. If the water contains the clay with 0,1 $\mathrm{kg} / \mathrm{m}^{3}, m=1$.If the water contains $0,1 \mathrm{~kg} / \mathrm{m}^{3}$ of these particles and more, $m>1 ; n$ coefficient taking into account the pulsation of speed in the bottom zone; $k$-is a coefficient characterizing the possible deviation of the adhesion force, equal to the average value.

$$
n=\left(u_{\Delta \max } / \bar{u}_{\Delta}\right)^{2}(k=0.5) .
$$

Here $u_{\Delta \max }$ and $\bar{u}_{\Delta}$ is the velocity at the bottom at the height of the maximum and average roughness. If $d<0.001 \mathrm{~m}$, then the stress coefficient is determined by the following formula.

$$
n=1+\frac{d}{0.00005+0.3 d}
$$

If $\mathrm{d}>0.001 \mathrm{~m}$, then the stress coefficient will $b_{e n}=4[7,8,9,13]$.

Particle movement and further movement with a stream of water is considered the most complex process. The proposed dependencies did not take into account all the factors. For example, when studying the non-washing speed in the channels of the trapezoidal section in the above dependencies was not taken into account its shape. The results of the above experiments make it necessary to take this factor into account. The force of the water flow, affecting the side slopes and bottom particles, is variable for turbulent movement. To study the non-washing speed of the side slopes and the bottom of the channel and the influence of pulsating loads during erosion, special experimental studies were conducted in a hydraulic chute (tray parameters 13.6 × $1.0 \times 0.8 \mathrm{~m})$. The trapezoidal channel shape model dimensions are as follows: (length of $8.5 \mathrm{~m}$, width along the bottom of $0.30 \mathrm{~m}$, depth of $0.15 \mathrm{~m}$, and slope $\mathrm{m}=2$ ). Along the length of the channel in various places, special places have been left for the location of soils. In experimental studies, sand particles with a diameter of $d \leq 0.315 \mathrm{~mm} ; \quad 0.315 \mathrm{~mm}<d \leq 0.63 \mathrm{~mm} ; \quad 0.63 \mathrm{~mm}<d \leq 1.25 \mathrm{~mm} \quad 1.25 \mathrm{~mm}<d \leq 2.5 \mathrm{~mm}$ 
During the research, were used existing hydraulic methods in this field. The experiments on determining the erosion velocity of disconnected soils show that with an increase in pulsations over the cross-section, the possibility of erosion of the flow with the same average velocities increases. At the same time, analysis of the data on pulsation velocities shows that the pulsation velocity is approximately two times higher than the averaged velocity. This factor must be considered when determining the active load of particles at the bottom of the channel [10-13].

Figure 1 shows a graph of the connection of average erosion velocity with particle diameter. According to the experimental data, observed simultaneous erosion of small sand particles at the side slopes and the bottom of the channel [12, 13]. The results of the obtained experimental data on the vertical average velocity show that the channel erosion begins, first of all, in the parts of the confluence of the side slopes and the bottom. Based on the experimental data, constructed a plot of the velocity distribution over the stream's depth (Figure 2). This graph observed conservation of velocity changes along with the depth of the flow in various flow regimes. In all experiments, were observed the smallest values of the flow velocity near the bottom and the largest value at a depth of $(0.8-0.9) \mathrm{h}$ from the level.

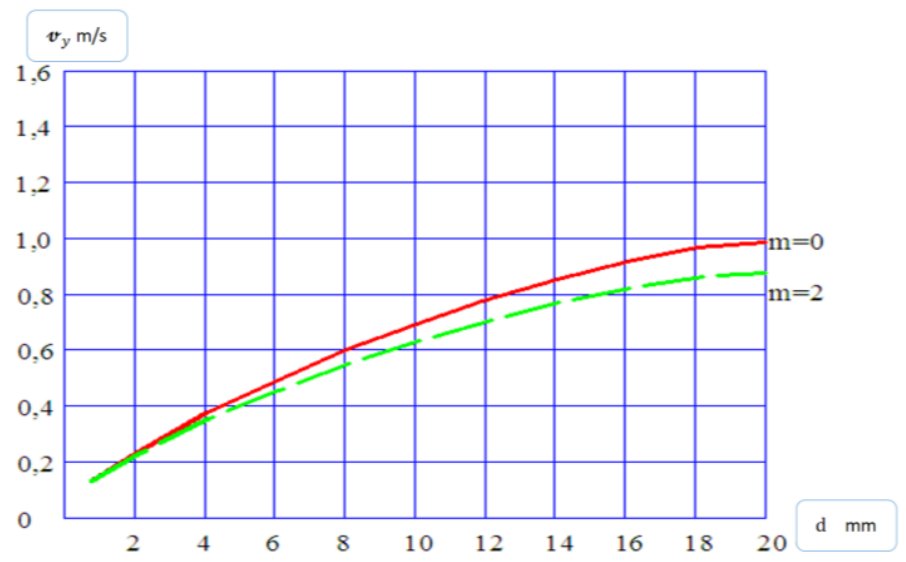

Fig.1 Dependence of the average erosion speed on the particle diameter

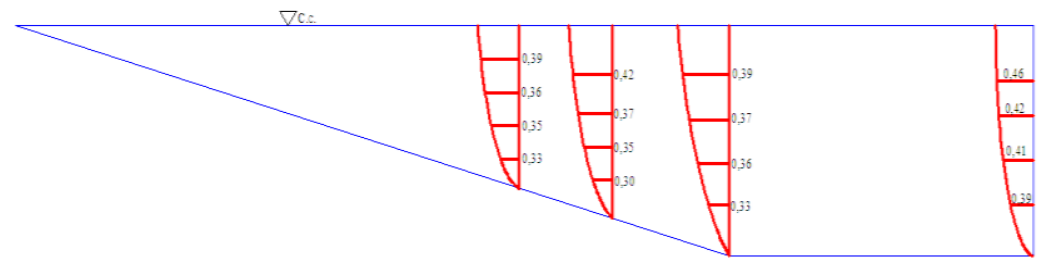

Fig.2. The vertical velocity distribution of the trapezoidal canal (channel slope $m=2$ )

This means that the pulsation condition of loads is an important factor in channel erosion; when studying the non-washing channel speed, there is a need to take them into account. In the experiments, taking into account the degree of turbulence and the distribution of flow velocities, based on the analysis of the obtained data, the dependences (1); (2) were improved.

\section{Results and Discussion}


Based on the above laboratory experiments, an analysis of the non-erosive velocity is carried out, taking into account the trapezoidal shape of the channel. Based on the analysis of the results of the studies, the coefficient " $\eta$ " is introduced into formula (1), taking into account the flow movement in the trapezoidal channel. Based on the analysis of the experimental data, the coefficient value is as follows: $\eta_{1}=1.41$ for the bottom of the channel and $\eta_{2}=1.52$ for side slopes. The following improved equation is proposed for the channel bottom:

$$
\begin{gathered}
\vartheta_{H}=\left(\lg \frac{8.8 h}{d_{o}}\right) \sqrt{\frac{2 m_{1}}{0.44 \cdot \eta_{1} \rho n_{1}}\left[g\left(\rho_{s}-\rho\right) d_{o}+2 C_{y_{1}}{ }^{H} K_{1}\right]} \\
\vartheta_{\Delta H}=1.25 \sqrt{\frac{2 m_{1}}{0.44 \cdot \eta_{1} \rho n_{1}}\left[g\left(\rho_{s}-\rho\right) d_{o}+2 C_{y_{1}}{ }^{H} K_{1}\right]}
\end{gathered}
$$

for side slopes:

$$
\begin{aligned}
& \vartheta_{H}=\left(\lg \frac{8.8 h}{d_{o}}\right) \sqrt{\frac{2 m_{1}}{0.44 \cdot \eta_{1} \rho n_{1}}\left[g\left(\rho_{s}-\rho\right) d_{o}+2 C_{y_{1}}{ }^{H} K_{1}\right]} \\
& \vartheta_{\Delta H}=1.25 \sqrt{\frac{2 m_{1}}{0.44 \cdot \eta_{1} \rho n_{1}}\left[g\left(\rho_{s}-\rho\right) d_{o}+2 C_{y_{1}}{ }^{H} K_{1}\right]}
\end{aligned}
$$

Comparing the calculated values according to the experimental data (5) and the formula showed sufficient proximity between the two (Figures 3 and 4).

A comparison of the calculated dependence according to operational data (5) and dependency (6) is shown in Figure 3.

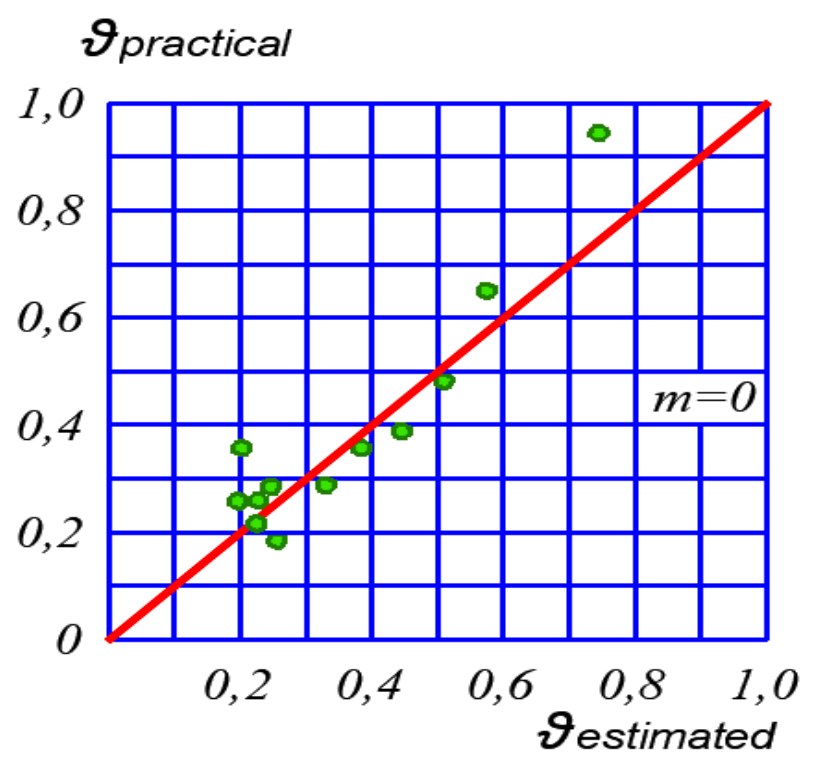

Fig-3. Comparison of experimental and calculated values of non-erosion speed in disconnected soils 


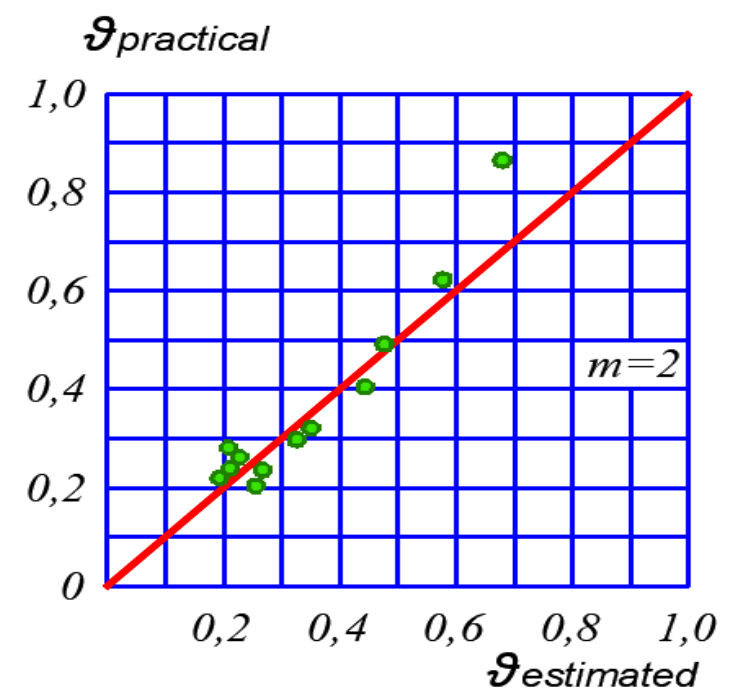

Fig-4. Comparison of experimental and calculated values of non-erosion speed in disconnected soils.

The obtained experimental points are located below in comparison with the calculated points in the graph. This can be explained by the fact that in the trapezoidal channels, under the influence of the degree of lateral slopes of the hydraulic regime, they are taken. A comparison of the calculated values according to the proposed improved dependence with the calculated values according to the formula of V.A. Velikanov, I.I. Levi, C.E. Mirtskhulava, B.I. Studenichnikova and A.M. Latyshenkov showed satisfactory results. Therefore, to determine the non-washing speed of the side slopes and the bottom of the trapezoidal canal with disconnected soil, it is proposed to use the formulas [5-9].

\section{Conclusions}

The non-washing flow speed was calculated in various ways and was considered the main reason for the large difference between the values obtained in the experiments; it is considered not to consider factors that determine the quantitative and qualitative regularities of the flow and the poured soil. These factors include the physical and technical properties of soils and flow turbulence. Therefore, when substantiating a method for predicting erosion, the physicomechanical properties of soils are determined based on control experiments; along with this, experimental studies have been carried out to establish the statistical characteristics of flow turbulence and the erosion velocity of these soils.

Based on the analysis of laboratory experiments, a modified dependence is proposed for establishing a non-blurring speed of channels with connected and disconnected soils, taking into account the trapezoidal shape of the channel. Based on the experimental values, the coefficients are as follows: $\eta_{1}=1.41$ for the channel bottom $\eta_{2}=1.52$ for side slopes.

\section{References}

1. Jurík, L', Zeleňáková, M.Kaletová, T., Arifjanov Small Water Reservoirs: Sources of Water for Irrigation. The handbook of environmental Chemistry. Volume 69, pp.115131. (2019)

2. W.Alawadi, T.D. Prasad, Osama Al-Salih Assessing the Impact of Velocity Dip and Wake Coefficients on Velocity Prediction for Open Channel Flows. Research Journal 
of Applied Sciences, Engineering and Technology 16(1): pp.9-14, (2019), DOI:10.19026/rjaset.16.5993.

3. A.Arifjanov, L.Samiev, Sh.Akmalov Dependence of Fractional Structure of River Sediments on Chemical Composition. International Journal of Innovative Technology and Exploring Engineering (IJITEE) ISSN: 2278-3075, Volume-9 Issue-1, November (2019)

4. ArifjanovA.M., FathulloevA.M. Dynamics of a suspended flow in the channels. Fan. p.124, Tashkent, (2014)

5. A.Arifjanov, M.Otaxonov, L.Samiev, Sh.Akmalov Hydraulic calculation of horizontal open drainages. E3S Web of Conferences 97, 05039 (2019). FORM-2019.

6. A.Arifjanov, L.Samiev, T.Apakhodjaeva, Sh.Akmalov Distribution of river sediment in channels. XII International Scientific Conference on Agricultural Machinery Industry. IOP Conf. Series: Earth and Environmental Science 403 (2019) 012153.

7. Arifjanov A. Distribution of suspended sediment in the stationary flow.Water resources.No2. Pp.185-187. (InRussian).Moscow, (2011)

8. M.Ikramova, Kh.Kabulov, I.Akhmedkhodjaeva, A.Khodjiev Amu-Surkhan Basin water use efficiency approach and its effect on energy saving. XII International Scientific Conference on Agricultural Machinery Industry. IOP Conf. Series: Earth and Environmental Science 403 (2019) 012156

9. Mirtskhulava T.E.Fundamentals of physics and mechanics of erosion channels. Hydrometoizdat. p.303.(In Russian) Leningrad, (1988)

10. P. Schuerch, A. L. Densmore, B. W. McArdell, and P. Molnar, "The influence of landsliding on sediment supply and channel change in a steep mountain catchment," Geomorphology, vol. 78, no. 3-4, pp.222-235, Aug. (2006).

11. M. Shahrokhi, F. Rostami, M. A. Md Said, and Syafalni, "Numerical modeling of baffle location effects on the flow pattern of primary sedimentation tanks," Appl. Math. Model., vol. 37, no. 6, pp. 4486-4496, Mar. (2013)

12. W. Reczyński, K. Szarłowicz, M. Jakubowska, P. Bitusik, and B. Kubica, "Comparison of the sediment composition in relation to basic chemical, physical, and geological factors," Int. J. Sediment Res., Jan. (2020)

13. R. Mazumder, "Sediment Provenance: Influence on Compositional Change From Source to Sink," Sediment Proven., pp. 1-4, Jan. (2017)

14. Vakhidova, U.A., Ibragimova, Z.I., Apakhodjaeva, T.U. Estimation of the temperature and humidity kinetics during the passage of vaporous moisture through textile materials (2020) IOP Conference Series: Earth and Environmental Science, 614 (1). DOI: $10.1088 / 1755-1315 / 614 / 1 / 012024$.

15. Abduraimova, D., Atakulov, D., Ibragimova, Z., Apakhodjaeva, T. Evaluation of erosion and accumulative process with using Geoinformation systems in water resource management (2019) International Conference on Information Science and Communications Technologies: Applications, Trends and Opportunities, ICISCT 2019. DOI: 10.1109/ICISCT47635.2019.9012020.

16. Samiyev, L., Allayorov, D., Atakulov, D., Babajanov, F. The influence of sedimentation reservoir on hydraulic parameters of irrigation channels, (2020) IOP Conference Series: Materials Science and Engineering, 883 (1), DOI: 10.1088/1757899X/883/1/012031.

17. Fatxulloyev, A., Abduraimova, D., Otakhonov, M., Atakulov, D., Samiev, L. Method designing of open drainages (2020) IOP Conference Series: Materials Science and Engineering, 883 (1),.DOI: 10.1088/1757-899X/883/1/012047.

18. Atakulov, D., Babajanov, F. Evaluation of the hydraulic and morfometric connections of the riverbed with using GIS (2020) IOP Conference Series: Materials Science and Engineering, 869 (4), DOI: 10.1088/1757-899X/869/4/042028. 
19. Abduraimova, D., Atakulov, D., Ibragimova, Z., Apakhodjaeva, T. Evaluation of erosion and accumulative process with using Geoinformation systems in water resource management, International Conference on Information Science and Communications Technologies: Applications, Trends and Opportunities, (2019), DOI: 10.1109/ICISCT47635.2019.9012020.

20. Fatxulloyev A., Allayorov D., Otakhonov M.Study of hydraulic parameters for concreting channels (2020) IOP Conference Series: Earth and Environmental Science, 614 (1).DOI: 10.1088/1755-1315/614/1/012054.

21. Fatxulloyev A., Gafarova, A., Otakhonov, M., Allayorov, D. The hydraulic efficiency of the soil channels (2020) IOP Conference Series: Materials Science and Engineering, 883 (1). DOI: 10.1088/1757-899X/883/1/012042.

22. Rakhimov Q., Allayorov, D., Ibragimova, Z. Increasing flow turbidity in pressure systems. (2020) IOP Conference Series: Materials Science and Engineering, 869 (7). DOI: 10.1088/1757-899X/869/7/072029.

23. Rakhimov K., Ahmedkhodjaeva Xoshimov S. Theoretical bases of hydraulic mixture in round cylindrical pipelines (2020) IOP Conference Series: Earth and Environmental Science, 614 (1). DOI: 10.1088/1755-1315/614/1/012095. 